
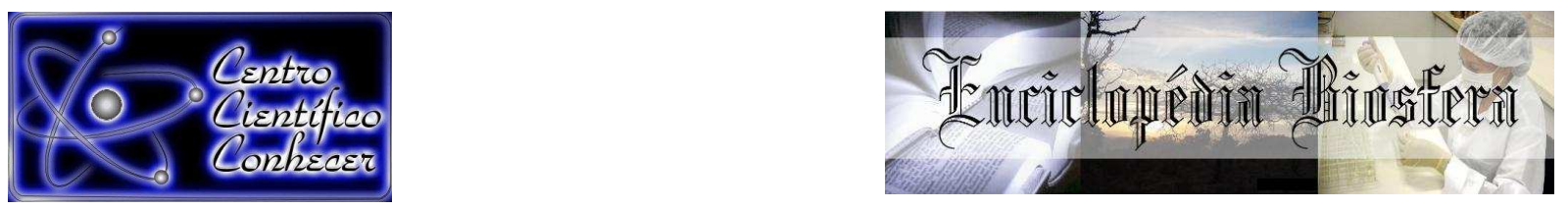

\title{
ANÁLISE ESPACIAL NA GESTÃO DE RECURSOS HÍDRICOS: BACIA HIDROGRÁFICA DO RIO URIBOCA, BELÉM, PARÁ
}

\footnotetext{
$\frac{\text { Leonardo Sousa dos Santos }}{1}{ }^{1}$ Carlos Benedito Barreiro Gutierrez ${ }^{2}$,
Nayara de Miranda Dias ${ }^{3}$ e Altem Nascimento Pontes ${ }^{4}$
${ }^{1}$ Geógrafo. Mestrando em Ciências Ambientais. Universidade do Estado do Pará.
leonardocbmpa@yahoo.com.br
${ }^{2}$ Tecnólogo em Processamento de dados. Mestrando em Ciências Ambientais.
Universidade do Estado do Pará.
${ }^{3}$ Advogada. Mestranda em Ciências Ambientais. Universidade do Estado do Pará.
${ }^{4}$ Professor e Pesquisador do Programa de Mestrado em Ciências Ambientais.
Universidade do Estado do Pará.
Recebido em: 08/09/2015 - Aprovado em: 14/11/2015 - Publicado em: 01/12/2015
DOI: http://dx.doi.org/10.18677/Enciclopedia_Biosfera_2015_078
}

\section{RESUMO}

A bacia hidrográfica do rio Uriboca (BHU) constitui-se em uma das bacias mais importantes que integra a bacia do rio Guamá. A BHU possui $59,44 \mathrm{~km}^{2}$ e um perímetro de $72,69 \mathrm{~km}$, localizada à margem direita do rio Guamá. A bacia também tem $54,45 \%$ da sua área inserida no parque ambiental Refúgio de Vida Silvestre Metrópole da Amazônia, na Região Metropolitana de Belém (REVIS), Estado do Pará. O objetivo geral do presente trabalho foi o estudo dos tipos de uso e cobertura da terra nas bacias hidrográficas do rio Uriboca, em especial nas áreas de preservação permanente, visando assim produzir dados e informações que possam ser utilizadas pelos órgãos competentes de maneira a subsidiar as políticas de planejamento e gestão ambiental da bacia hidrográfica estudada. Utilizaram-se tecnologias, metodologia de geoprocessamento e estrutura matricial Raster MDE/SRTM para preparação e extração de dados (área da bacia e rede de drenagem), cálculos dos parâmetros físicos e elaboração de mapas digitais (hierarquia fluvial, altimetria e declividade). Com a análise da BHU melhorou o entendimento dos elementos físicos, em especial ligados à hidrografia, como também, desenvolveu um produto de importância substancial para o planejamento, proteção do meio ambiente e estudos morfométricos. A BHU é essencial para a manutenção do equilíbrio ambiental do REVIS e os resultados apontam que em razão do número total de canais existentes, a bacia é sensível a alterações, despertando para a importância e a necessidade de estudos e pesquisas, a fim de identificar alterações que ameaçam o equilíbrio desta região.

PALAVRAS-CHAVE: Delimitação automática. SRTM.Uso e cobertura da terra 


\title{
ANALYSIS SPACE IN WATER RESOURCES MANAGEMENT: THE RIVER RIVER BASIN URIBOCA, BELÉM, PARÁ
}

\begin{abstract}
The basin of Uriboca river (BHU) is in one of the most important basins which include the basin of the river Guamá. The BHU has $59,44 \mathrm{~km}^{2}$ and a perimeter of $72,69 \mathrm{~km}$, located on the right bank of the river Guamá. The basin also has $54.45 \%$ of its area inserted in the environmental park Wildlife Refuge metropolis of the Amazon, the metropolitan area of Belém (REVIS), Pará State. The overall goal of this work is the study of the types of use and land occupation in watersheds Uriboca, particularly in the areas of permanent preservation, thus aiming to produce data and information that could be used by the competent bodies in order to subsidize the policy planning and environmental management of the studied watershed. We used GIS technology and methodology and matrix structure Raster MDE/SRTM preparation and data extraction (the basin and drainage network), the physical parameters calculations and preparation of digital maps (fluvial hierarchy, altimetry and slope). With the analysis of BHU improve the understanding of the physical elements, especially related to hydrography as well; it developed a product of substantial importance for the planning, environmental protection and morphometric studies. The BHU is extremely essential for maintaining the environmental balance of the REVIS and the results show that because of the total number of channels, the basin is sensitive to change, awakening to the importance and the need for studies and research in order to identify changes that threaten to destabilize the region.
\end{abstract}

KEYWORDS: Use and land cover. SRTM. Automatic delineation.

\section{INTRODUÇÃO}

A expressão bacia hidrográfica é usada para denotar a área de captação natural da água de precipitação que faz convergir os escoamentos para um único ponto de saída, que é chamado de exutório (BIELENKI, 2012). A formação da bacia hidrográfica se dá por meio dos desníveis do terreno os quais orientam os cursos da água, sempre de áreas mais altas para as mais baixas. As bacias hidrográficas são unidades espaciais de dimensões variadas, que vêm sendo adotadas como áreas preferenciais para gestão das águas superficiais ou subterrâneas disponíveis para qualquer tipo de uso (CARVALHO, 2010).

Nos últimos anos, a gestão, o manejo e a preservação de bacias hidrográficas tornaram-se temas relevantes, visto que as consequências da falta de conservação e proteção das fontes de água podem ocasionar contaminação das águas superficiais ou subterrâneas (SOUZA et al., 2012). Ambientalmente, pode-se dizer que a bacia hidrográfica é a unidade ecossistêmica e morfológica que melhor reflete os impactos das interferências antrópicas (JENKINS et al., 1994). Logo, o conhecimento das características de uma bacia hidrográfica é de suma importância para condução de propostas de gestão dos recursos hídricos, com vista para o uso e manejo sustentáveis.

As bacias hidrográficas são unidades territoriais importantes para a implementação da Política Nacional de Recursos Hídricos e atuação do Sistema Nacional de Gerenciamento dos Recursos Hídricos. Sua análise integrada, no espaço e no tempo, permite entendimento das suas dinâmicas local e regional, apoiando o gerenciamento dos recursos hídricos (GUEDES \& SILVA, 2012).

ENCICLOPÉDIA BIOSFERA, Centro Científico Conhecer - Goiânia, v.11 n.22; p.162 
Parâmetros como área de drenagem, declividade, relevo, uso do solo, dentre outros, se mostram como variantes ambientais dentro do processo de gestão hídrica dos rios de qualquer área. A gestão de recursos hídricos acontece no momento em que a velocidade de degradação dos corpos hídricos, na maioria dos casos, é superior a capacidade de renovação.

Problemas de degradação dos corpos hídricos vêm afetando as médias e grandes cidades brasileiras. Nesse sentido, a gestão dos recursos hídricos tem como fim assegurar a disponibilidade de água, no que diz respeito à quantidade e qualidade da água. Sendo a bacia uma unidade de planejamento, uma vez que nas bacias hidrográficas, tanto o uso e cobertura da terra quanto às atividades econômicas e as atividades sociais, refletem os problemas ambientais e as potencialidades da região (SANTOS et al., 2013).

Desta forma, o objetivo geral do presente trabalho foi o estudo dos tipos de uso e cobertura da terra nas bacias hidrográficas do rio Uriboca, em especial nas áreas de preservação permanente, visando assim produzir dados e informações que possam ser utilizadas pelos órgãos competentes de maneira a subsidiar as políticas de planejamento e gestão ambiental da bacia hidrográfica estudada.

\section{MATERIAL E MÉTODOS}

Para o referido estudo, foi construída uma base de dados georreferenciados, com planos de informações, em escala de 1:55.000. Nessa etapa, foram utilizadas como apoio ferramentas de integração e análise de dados georreferenciados Q.Gis 2.8, versão "Wien", licenciado pela "General Public License" (GNU), que conjuga funções de processamento de imagens, análises espaciais, modelagem numérica de terreno e consulta a banco de dados espaciais.

Foi utilizada também a estrutura matricial Raster MDE-SRTM para preparação e extração de dados (área da bacia e rede de drenagem), cálculos dos parâmetros físicos e elaboração de mapas digitais (hierarquia fluvial, altimetria e declividade). Dados do Shuttle Radar Topography Mission (SRTM) constituem uma alternativa viável em análise espacial na gestão de recursos hídricos, principalmente para extração de bacias, altimetria, drenagem e extensão dos rios (BRUBACHER et al., 2012).

$\mathrm{Na}$ preparação e extração de dados MDE-STRM utilizou-se o conjunto de ferramentas para construção de análises hidrológicas com base no Modelo Digital de Elevação (MDE) do programa "Terrain Analysis Using Digital Elevation Models" (TauDEM) do Q.Gis 2.8.

O TauDEM é um algoritmo incorporado ao conjunto de ferramentas do Q.Gis que possibilitou extrair informações úteis de dados matriciais de SRTM para os processos de simulação hidrológica, incluindo rede de drenagem, comprimentos de redes de drenagem, pontos de drenagem, área, perímetro, bacia hidrográfica, conforme Figura 1. Esses dados garantem assertividade na gestão hídrica e manejo dos recursos hídricos, uma vez que as informações da localização são disponibilizadas em mapas digitais passíveis de serem atualizados. 


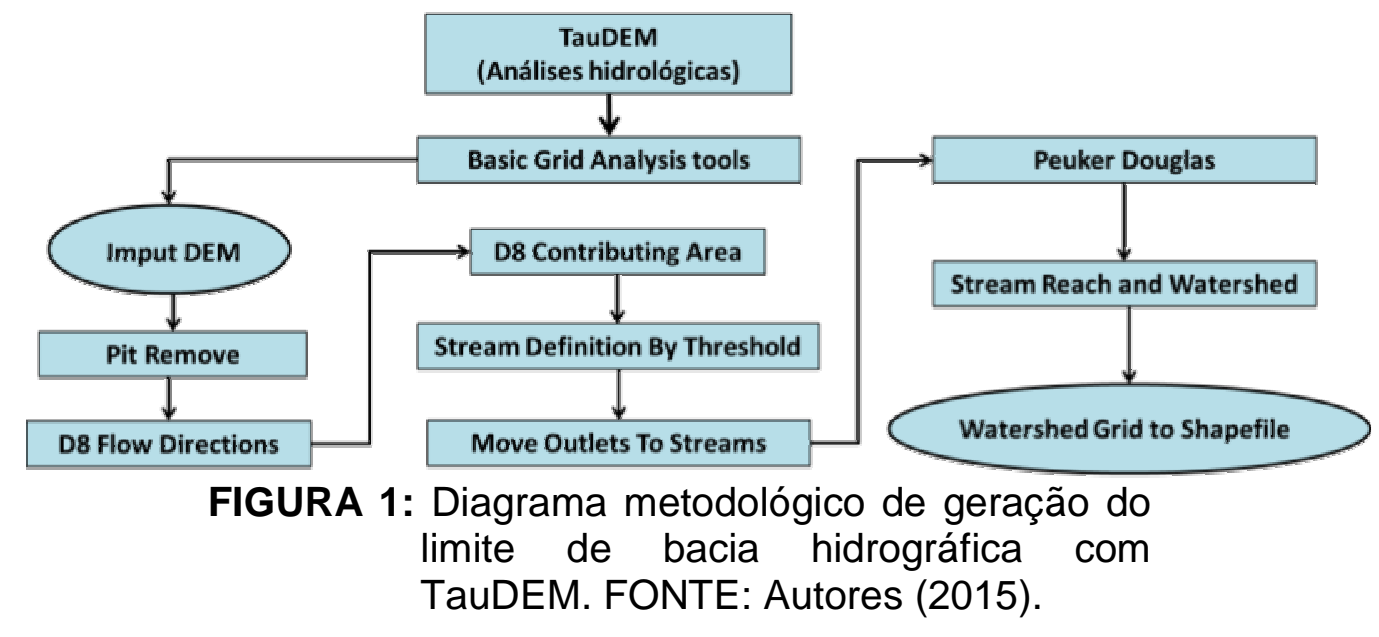

\section{Área de estudo}

O estudo foi conduzido em uma área experimental inserida na Região Metropolitana de Belém, PA, de coordenada central UTM, Zona 22S: Longitude: 799.511 e Latitude 9.843.180, denominada de bacia hidrográfica do Uriboca (BHU). A BHU constitui-se em uma das mais importantes que integra a bacia do rio Guamá e possui $5.944,71$ ha e perímetro de $72,69 \mathrm{~km}$, localizada à margem direita do rio Guamá.

A bacia tem $54,45 \%$ da sua área inserida no parque ambiental Refúgio de Vida Silvestre Metrópole da Amazônia (REVIS), que na década de 1940, pertencia à histórica Fazenda Guamá que foi doada à empresa Pirelli-Cia e onde era cultivada a Hevea brasiliensis e funcionava o antigo engenho do Uriboca para produção de borracha natural (RIBEIRO et al., 2007).

A bacia também possui $4,84 \%$ da sua área pertencente à comunidade quilombola Abacatal/Aurá, onde vivem 80 famílias que residem a distância de 8.792,17 $\mathrm{m}$ da PA-483 (Alça viária). Neste local foi instalado um posto de fiscalização do Batalhão de Polícia Ambiental (BPA), na Região Metropolitana de Belém, Estado do Pará, conforme Figura 2.

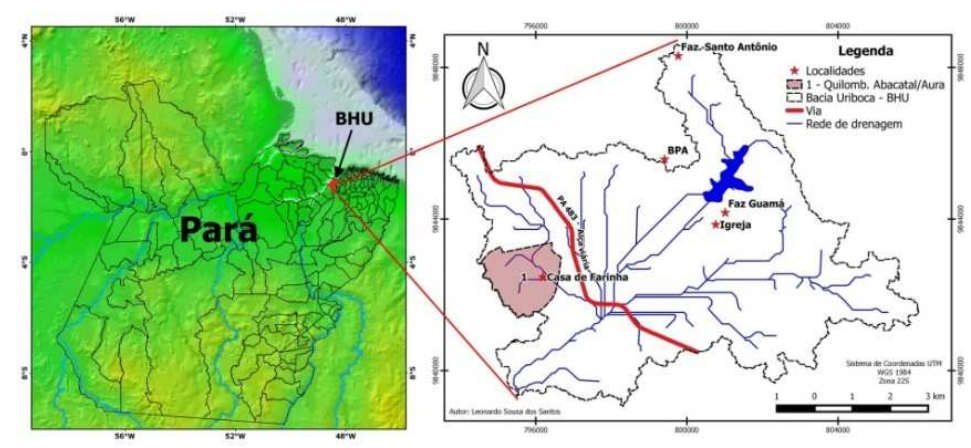

FIGURA 2: Localização da área de estudo.

FONTE: Autores (2015).

O clima na BHU é tropical úmido, cuja temperatura durante todo o ano chega à média de $26^{\circ} \mathrm{C}$. Os meses mais quentes estão compreendidos entre agosto e dezembro. Nessa época, a média das máximas chega a $32^{\circ} \mathrm{C}$, e a média das mínimas 
chega a $22^{\circ} \mathrm{C}$. A precipitação pluviométrica média anual atinge $2.500 \mathrm{~mm}$. A umidade relativa do ar chega a $85 \%$.

\section{RESULTADOS E DISCUSSÃO}

De acordo com os resultados, verificou-se que a BHU apresenta uma área de $59,44 \mathrm{~km}^{2}$, com comprimento total de $73.589,25 \mathrm{~m}$ de canais. O perímetro, comprimento da linha imaginária ao longo do divisor de águas, é de 72.699,97 m. A extensão do comprimento do eixo principal (rio Uriboca) é de 12.116,31 m. Outras características físicas da bacia identificada resultaram em um conjunto de informações descritas na Tabela 1.

TABELA 1: Dados obtidos da bacia hidrográfica do rio Uriboca.

\begin{tabular}{lcc}
\hline \multicolumn{1}{c}{ Características físicas } & \multirow{2}{*}{ Unidades } & Bacia \\
\cline { 3 - 4 } & Rio Uriboca \\
\hline Área da bacia & $\mathrm{km}^{2}$ & 59,44 \\
Perímetro da bacia & $\mathrm{m}$ & $72.699,97$ \\
Número de canais & Und & 49 \\
\hline Comprimento do eixo principal da bacia & $\mathrm{km}$ & $12.116,31$ \\
Comprimento total do curso d'água & $\mathrm{m}$ & $73.589,25$ \\
Comprimento mínimo dos canais & $\mathrm{m}$ & 68,88 \\
Comprimento máximo dos canais & $\mathrm{m}$ & $6.736,99$ \\
Médias dos canais & $\mathrm{m}$ & $1.501,82$ \\
Ordem da sub-bacia & - & $4 \underline{a}$ \\
Números de nascentes & - & 38 \\
\hline
\end{tabular}

Fonte: Autores (2015).

Com a análise dos dados de modelo digital de elevação identificou-se que a BHU possui uma direção de fluxo (escoamento) no sentido Oeste (cor azul) e Sul (cor preta), representando $26 \%\left(15,50 \mathrm{~km}^{2}\right)$ e $25 \%\left(15,29 \mathrm{~km}^{2}\right)$, respectivamente, da direção de fluxo na área em estudo (Figura 3a). O terceiro maior valor de direção de fluxo ocorreu na direção Norte (cor verde claro), representando $12 \%\left(7,64 \mathrm{~km}^{2}\right)$ da bacia do Uriboca (Figura 3a).

$\mathrm{Na}$ Figura 3a, observa-se o mapa com as características de direção de fluxo da bacia do rio Uriboca onde é possível, com base na grade regular de direção de fluxo, também identificar o valor do fluxo acumulado, que corresponde à localização do fluxo de captação da rede hidrográfica entre pontos diferentes dentro da BHU. A direção de fluxo é indispensável para que uma drenagem funcional possa existir (RENNÓ et al., 2008).

$\mathrm{Na}$ Figura 3b, tem-se o mapa de fluxo de acúmulo. Em relação à rede de drenagem do rio Uriboca, os canais de $1^{1}$ a ordem obtiveram intensidade de acúmulo de

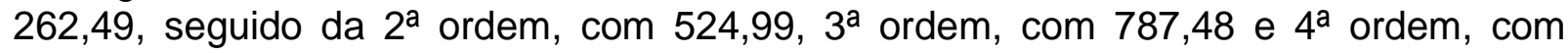
$1.049,48$, representando um crescimento médio de 1,5 na área de captação da rede de drenagem, conforme se observa com a intensidade da cor azul da rede de drenagem (Figura 3b). Os mapas de direção de fluxo (Figura 3a) e acumulação de fluxo (Figura 3b) possibilitam uma visão diferenciada da rede de drenagens para gestão dos recursos hídricos. 

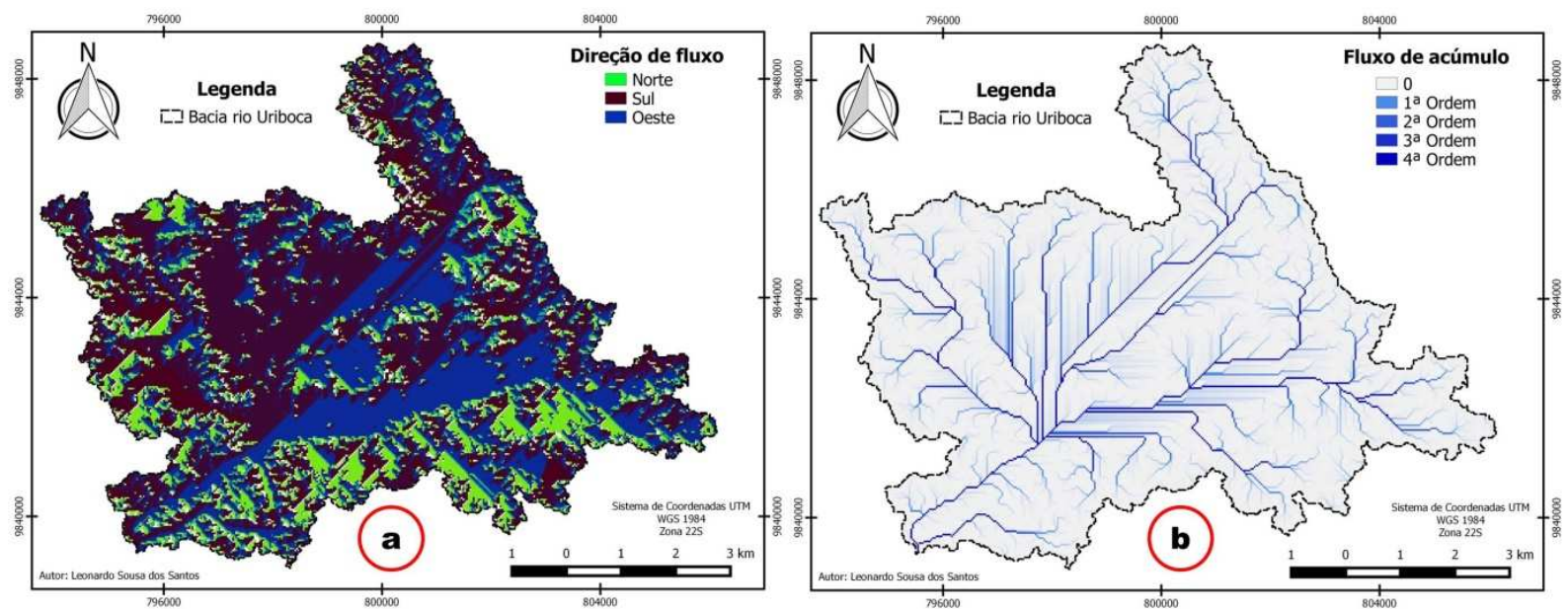

FIGURA 3: Mapa de direção de fluxo e Mapa de acúmulo de fluxo da bacia do rio Uriboca.

FONTE: Autores (2015).

O intervalo altimétrico de 5 a 10 metros representou a maior área na $\mathrm{BHU}$, com $31,46 \mathrm{~km}^{2}$ (Figura 3a). As altimetrias no intervalo de 10 a 20 metros representaram o segundo intervalo com maior valor de áreas, totalizando $35,70 \mathrm{~km}^{2}$. As altimetrias no intervalo de 40 a 57 metros representaram o menor valor de área, com 0,03 km². Ou seja, 52,93\% da BHU possui um nivelamento vertical do terreno entre 5 a 10 metros. Outras características altimétricas da bacia resultaram em um conjunto de informações descritas na Tabela 2.

TABELA 2: Distribuição das classes de altimetria para a bacia hidrográfica do rio Uriboca

\begin{tabular}{|c|c|c|}
\hline Classes de Altimetria (m) & $\left(\mathrm{km}^{2}\right)$ & $\%$ \\
\hline $5-10$ & 31,46 & 52,93 \\
\hline $10-20$ & 21,22 & 35,70 \\
\hline $20-30$ & 4,31 & 7,26 \\
\hline $30-40$ & 2,40 & 4,05 \\
\hline $40-57$ & 0,03 & 0,06 \\
\hline Total & 59,44 & 100 \\
\hline
\end{tabular}

FONTE: Autores (2015).

Em termo de declividade, nas áreas planas (Figura 3b) foram obtidos os maiores valores, com $35,73 \mathrm{~km}^{2}$. A classe de declividade Forte ondulada totalizou uma extensão de $0,24 \mathrm{~km}^{2}$. Outras classes de declividade foram: Suave ondulado com 1,84 km², Ondulado com 5,03 km², conforme informações descritas na Tabela 3. 
TABELA 3: Distribuição das classes de declividade para a bacia hidrográfica do rio Uriboca

\begin{tabular}{|c|c|c|c|}
\hline$\%$ & Classes de Declividade & $\mathbf{k m}^{2}$ & $\%$ \\
\hline $\begin{array}{c}0-3 \\
3-8 \\
8-20 \\
20-45\end{array}$ & $\begin{array}{c}\text { Plano } \\
\text { Suave ondulado } \\
\text { Ondulado } \\
\text { Forte ondulado }\end{array}$ & $\begin{array}{c}35,73 \\
1,84 \\
5,03 \\
0,24\end{array}$ & $\begin{array}{l}\mathbf{6 1 , 1 1} \\
31,01 \\
8,47 \\
\mathbf{0 , 4 1}\end{array}$ \\
\hline & Total & 59,44 & 100 \\
\hline
\end{tabular}

FONTE: Adaptado de EMBRAPA, 1979.

Nas Figuras 4a e 4b, observa-se visualmente que a distribuição altimétrica, no intervalo de 5 a 10 metros, está inserida em áreas planas na $\mathrm{BHU}$.
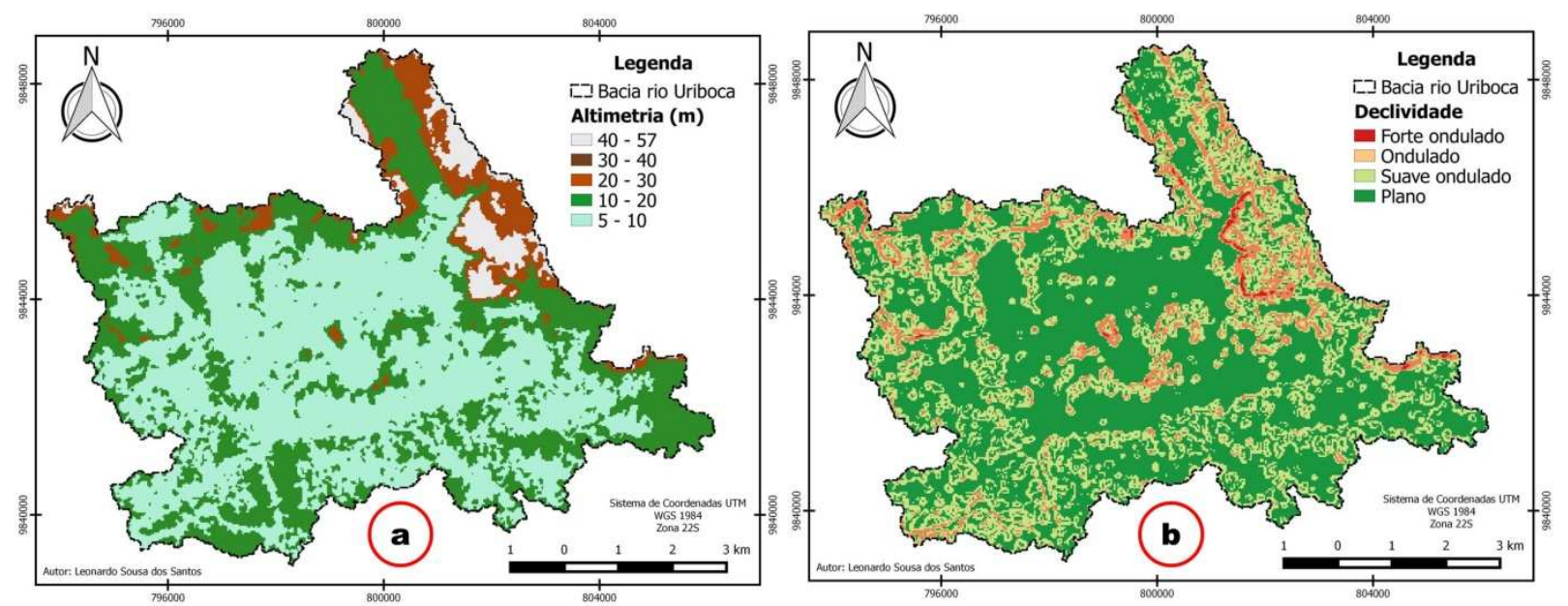

FIGURA 4: Mapa de altimetria e Mapa de declividade da bacia do rio Uriboca.

FONTE: Autores (2015).

Observa-se na Figura 5a que a rede de drenagem da BHA possui um padrão de forma que lembra as nervuras de uma folha vegetal, caracterizando ser uma bacia com padrão de drenagem dendrítica. Com relação às características da hierarquia fluvial, na Figura 5b, proposta por STRAHLER (1952), a calha principal do rio Uriboca pertence à $4^{\mathrm{a}}$ ordem, sendo considerado como um rio de médio porte.

Identificou-se que a rede de drenagem da BHU esta distribuída em 38 canais de $1^{\text {a }}$ ordem com 40,54 km de extensão, oito canais de $2^{\text {a }}$ ordem, com $25,43 \mathrm{~km}, 2$ canais de $3^{\text {a }}$ ordem com $3661,55 \mathrm{~m}$ e 1 canal de $4^{\text {a }}$ ordem medindo 3945,37 m totalizando um sistema de drenagem com 49 canais, com comprimeto total de 73,58 km de extensão de curso d'água.

$\mathrm{Na}$ Figura 5b estão representados os menores canais sem tributários que são considerados de primeira ordem; os canais de segunda ordem surgem da confluência de dois canais de primeira ordem, e só recebem afluentes de primeira ordem; os canais de terceira ordem surgem da confluência de dois canais de segunda ordem, podendo receber afluentes de segunda e primeira ordens; os canais de quarta ordem surgem da confluência de canais de terceira ordem, podendo receber tributários de ordens inferiores, e assim sucessivamente (BIELENKI, 2012). 
De acordo com MORAIS (2010), o processo de hierarquização e ordenação dos canais é importante, pois facilita os estudos físicos da rede de drenagem de uma da bacia, permitindo uma maior aproximação com a bacia estudada.

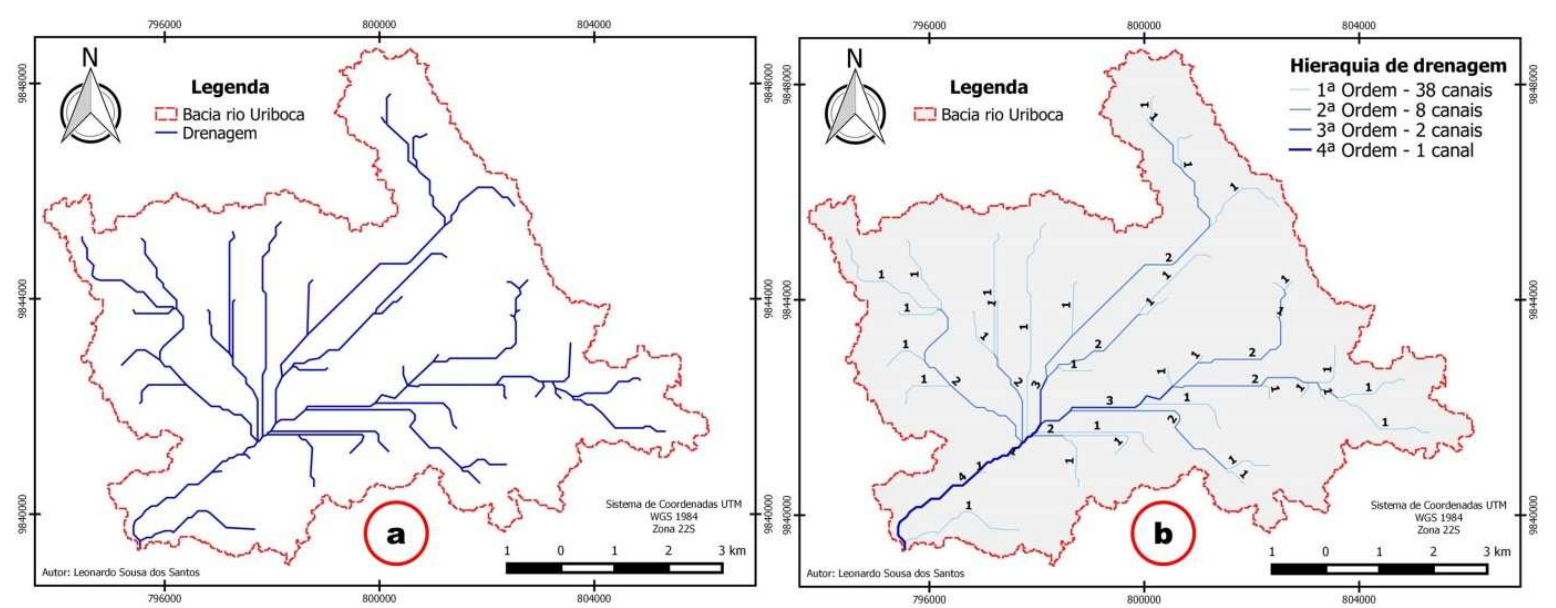

FIGURA 5: Mapa da rede de drenagem e Mapa da hierarquia fluvial da bacia do rio Uriboca.

FONTE: Autores (2015).

As alterações no uso cobertura da terra em bacias hidrográficas têm resultado em severas mudanças nas características do escoamento superficial. Com o mapeamento do uso e cobertura da terra (Figura 6), observou-se que 53,16\% (31,60 $\left.\mathrm{km}^{2}\right)$ da BHU é ocupada por floresta, seguido da vegetação secundária $(26,91 \%)$, Área urbana $(10,43 \%)$, conforme descrito na Tabela 4.

$\mathrm{Na}$ gestão de recurso hídrico sabe-se que a cobertura vegetal é um importante agente retardador do escoamento superficial, facilitando a infiltração da água. Sem essa proteção o solo fica mais vulnerável à compactação (impermeabilização) e aumenta os riscos de degradação dos solos, assoreamentos e alagamentos (TONIOLO et al., 2013). Nesse sentido, a BHU, com 53,16\% $\left(31,60 \mathrm{~km}^{2}\right)$ de floresta, apresenta pouco potencial para problemas ambientais.

TABELA 4: Distribuição das classes de uso e cobertura da terra para a bacia hidrográfica do rio Uriboca.

\begin{tabular}{c|c|c}
\hline Classes de Uso e Cobertura da Terra & $\left.\mathbf{( k m}^{\mathbf{2}}\right)$ & $\%$ \\
\hline Floresta & $\mathbf{3 1 , 6 0}$ & $\mathbf{5 3 , 1 6}$ \\
Vegetação secundária & 16,00 & 26,91 \\
Área urbana & 6,20 & 10,43 \\
Área não observada & 2,46 & 4,15 \\
Regeneração com pasto & 1,30 & 2,20 \\
Ocupações & 0,92 & 1,56 \\
Mineração & 0,63 & 1,07 \\
Hidrografia & 0,30 & 0,50 \\
\hline Total & $\mathbf{5 9 , 4 4}$ & $\mathbf{1 0 0}$ \\
\hline
\end{tabular}

FONTE: Autores (2015). 
Nos estudos para gestão de recurso hídrico as áreas de nascentes têm papel fundamental na conservação da bacia, pois nestes cursos de água, canais de 1a ordem, que 0 aquífero atinge a superfície e, consequentemente, a água armazenada no subsolo emerge na superfície do solo. Com os pontos de nascentes e rede de drenagem, identificou-se as áreas de proteção permanente (APP). A identificação das APP é importante para permitir o fluxo gênico e promover a gestão e melhoria dos recursos hídricos e demais funções ecológicas da área de estudo (CATELANI et al., 2012).

As 38 nascentes e as margens dos cursos d’água na BHU totalizaram área de $0,20 \mathrm{~km}^{2}$ e 4,39 $\mathrm{km}^{2}$, respectivamente, correspondendo a $0,48 \%$ e 7,38\% da área em estudo (Tabela 5).

TABELA 5: Distribuição das classes de classe de APP para a bacia hidrográfica do rio Uriboca

\begin{tabular}{|c|c|c|}
\hline \multirow{2}{*}{ Área de Proteção Permanente (APP) } & \multicolumn{2}{|c|}{ Área } \\
\hline & $\mathrm{km}^{2}$ & (\%) \\
\hline Nascente e suas áreas de contribuição (50 m) & 0,29 & 0,48 \\
\hline Margem dos cursos d'água $(30 \mathrm{~m})$ & 4,39 & 7,38 \\
\hline Total & 4,68 & 7,86 \\
\hline
\end{tabular}

FONTE: Autores (2015).

$\mathrm{Na}$ Figura 5, observa-se a distribuição das nascentes e cursos d’água, bem como a distribuição de classe de uso cobertura da terra na BHU. Identificou-se com a sobreposição dos dados que sete nascentes (18\% da APP de nascentes) estão em áreas de uso antrópico e duas ( $5 \%$ da APP de nascentes) em área de mineração na $\mathrm{BHU}$.

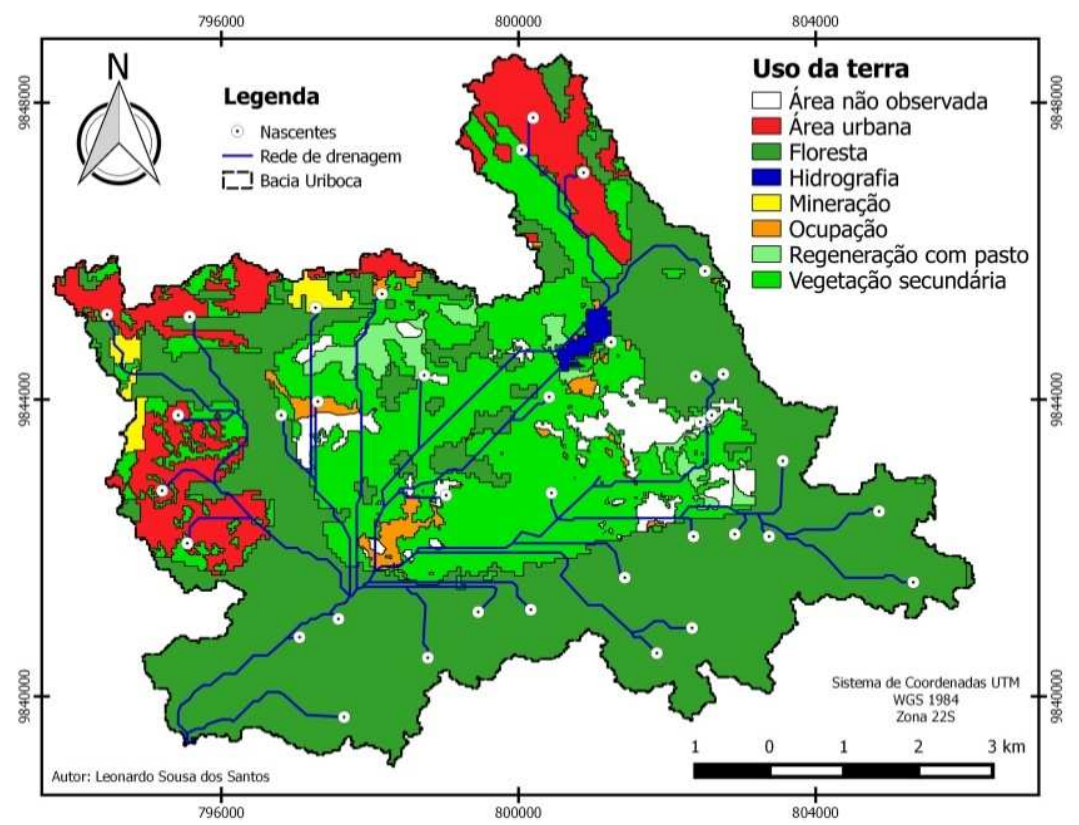

FIGURA 6: Mapa de Uso e cobertura da terra da bacia do rio Uriboca.

FONTE: Autores (2015). 
Os resultados indicam que as áreas de APPs, que por lei deveriam ser ocupadas pela vegetação nativa, estão sendo ocupadas por área urbanas, ocupações, vegetação secundária, regeneração com pasto e mineração, deixando de realizar as suas funções ambientais para a manutenção do equilíbrio ambiental na BHU.

\section{CONCLUSÕES}

Os problemas relativos à água são comumente tratados pensando na bacia hidrográfica onde estão inseridos, cuja delimitação prevalece sobre os limites municipais e estaduais. Nesse sentido, se reforça a importância que deve ser dada ao ato de registrar e armazenar, de forma precisa, integrada e sistemática, os dados relativos aos recursos hídricos, a fim de garantir uma fonte de informação confiável para a modelagem e gestão das bacias hidrográficas.

Com base nos resultados, conclui-se que a rede de drenagem da BHU converge para um ponto, significando que os impactos, ações e intervenções na referida bacia podem repercutir em toda sua extensão. A perda de vegetação no entorno e no centro da área da bacia, próximo as nascentes, deve provocar a maior geração de escoamento superficial, que será sentido em toda rede hidrográfica da BHU. Os $6 \mathrm{~km}^{2}$ de área urbana na BHU e próximo as nascentes podem provocar o lançamento de efluentes residenciais em um determinado ponto e isso irá influir na qualidade da água, bem como nos demais cursos d'água.

O conhecimento por ora adquirido com o presente estudo não encerra os levantamentos da BHU, ao contrário, abre novas possibilidades de aprofundamento de estudos de gestão de recursos hídricos, como também a atualização e/ou detalhamento de informações que poderão subsidiar um plano de manejo, de acordo com o que preceituam os órgãos de controle ambiental.

Pelas informações geradas, sugere-se que haja uma especial atenção para que sejam preservadas as vertentes da bacia hidrográfica do rio Uriboca, com práticas conservacionistas para manutenção dos cursos d'água, principalmente como, bebedouro, irrigação, e abastecimento de água para os $54,45 \%$ da BHU que pertence a REVIS e seu entorno.

Com a metodologia proposta, verifica-se que os dados espaciais obtidos podem ser utilizados na gestão dos recursos hídricos e consequentemente para a tomada de decisões. Ao final da análise, conclui-se que o trabalho agrega um valor substancial para apoio à tomada de decisão na $\mathrm{BHU}$ e ainda pode envolver estudos geológicos, geomoforlógicos, solo e vegetação. Desta forma, as informações aqui apresentadas podem servir para subisidiar um plano de conservação e serviços dos recursos hídricos do rio Uriboca.

\section{REFERÊNCIAS}

BIELENKI, J. Geoprocessamento e recursos hídricos: aplicações práticas. São Paulo. EduFCar. 2012. 257 p.

BRUBACHER, J. P.; OLIVEIRA, G. G.; GUASSELLI, L. A.; LUERCE, T. D. Avaliação 
de Bases SRTM para Extração de variáveis morfométricas e de drenagem. Geociência, São Paulo, v. 31, n.3, p. 381-393. 2012.

CARVALHO, R. G. As Bacias Hidrográficas Enquanto Unidade de Planejamento e Zoneamento Ambiental no Brasil. Caderno Prudentino de Geografia, Presidente Prudente, Volume Especial, n. 36, p. 26-43, 2014.

CATELANI, C. S.; BATISTA, G. T.; TARGA, M. S.; DIAS, N. W. Determinação de áreas prioritárias para o restabelecimento da cobertura florestal, apoiada no uso de geotecnologias. Ambi-Agua, Taubaté, v. 7, n. 3, p. 113-126, 2012.

EMBRAPA-CNPS. Centro Nacional de Pesquisa de Solos. Sistema brasileiro de classificação de solos. Brasília: Embrapa-SPI, 1979. 412 p.

GUEDES, H. A. S.; SILVA, D. D. Comparison between hydrographically conditioned digital. Revista Engenharia Agrícola, v. 32, n. 5, p. 932-943, 2012. http://dx.doi.org/10. 1590/S0100- 69162012000500012 elevation models in the morphometric characterization of watersheds.

MORAIS, F \& ALMEIDA, L. Geomorfologia Fluvial da Bacia Hidrográfica do Ribeirão Jaú, Palmas, estado do Tocantins. Brazilian Geographical Journal: Geosciences and Humanities research medium, Uberlândia, v. 1, n. 2, p. 331-351, Jul./Dec. 2010.

RENNÓ, C. D.; NOBRE, A.D.; CUARTAS, L. A.; SOARES, J. V.; HODNETT, M. G.; TOMASELLA, J.; WATERLOO, M. J. Hand, a new terrain descriptor using SRTM-DEM: Mapping terra-firme rainforest environments in Amazonia. Remote Sensing of Environment, New York, v.112, n.9, p.3469-3481, 2008.

RIBEIRO, A. S., PALHA, M. D. C.; TOURINHO, M. M.; WHITEMAN, C. W.; SILVA, A. S. L. Utilização dos recursos naturais por comunidades humanas do Parque Ecoturístico do Guamá, Belém, Pará. Acta Amazônica. v. 37, n.2, pp. 235-240.2007.

SANTOS, K. P.; OLIVEIRA, W. N.; KOPP, K. Geoprocessamento como um Instrumento para a Gestão dos Recursos Hídricos e Gestão Territorial nas Microbacias Foz Ribeirão dos Pereiras/Rio Anicuns e Microbacia Ribeirão das Pereiras - Goiás. Anais XVI Simpósio de Sensoriamento Remoto - SBSR, Foz do Iguaçu, PR, Brasil, Abril de 2013. INPE.

SOUZA, A. C.; FARIAS M. R.; DIAS, N. S. Gestão de Recursos Hídricos: O Caso da Bacia Hidrográfica Apodi/Mossoró (RN). Irriga Botucatu, v. 1, n. 1, Edição Especial, p. 280-296, 2012.

STRAHLER, A. N. Hypsometric (area-altitude) analysis and erosional topography. Geological Society of America Bulletin, v. 63, p.1117-1142, 1952.

TONIOLO, G. R.; LACRUZ, M. S. P.; SAUSEM, T. M. Análise do Escoamento 
Superficial na Bacia Hidrográfica do Vacacaí-Vacacaí Mirim. Revista Brasileira de Cartografia, n. 65/3, p. 605-615, 2013. 